\title{
An anomaly in U.S. SIDS data reported in the CDC wonder.cdc.gov mortality database
}

\author{
David T. Mage
}

Published online: 3 August 2012

(C) Springer Science+Business Media, LLC 2012

The cause of the Sudden Infant Death Syndrome (SIDS) is unknown and researchers often have to rely on the accuracy of epidemiologic data for generating and testing hypotheses. One such comprehensive database maintained by the U.S. Centers for Disease Control and Prevention (CDC) is found at http://wonder.cdc.gov/. However, it appears to contain an anomaly in reporting the location of SIDS death as the location where the infant was pronounced dead, as shown in the table below.

\begin{tabular}{lr}
\hline Location of all SIDS deaths, 10ICD R95, 1999-2009, U.S. & Totals \\
\hline Medical facility-inpatient & 1,923 \\
Medical facility_outpatient or ER & 12,933 \\
Medical facility—dead on arrival & 2,643 \\
Medical facility—status unknown & 66 \\
Decedent's home & 6,862 \\
Hospice facility & 1 \\
Nursing home/long term care & 27 \\
Other & 1,072 \\
Place of death unknown & 166 \\
Total SIDS at all locations & 25,693 \\
\hline
\end{tabular}

When SIDS occurs at home, the infant is almost always found nonresponsive, and most likely already dead. On the faint possibility that the infant is still alive but moribund, the parents or caregivers may immediately take the infant either by ambulance or private vehicle to the nearest medical facility (MF) in the hope of resuscitation. However, during this period, 1999-2009, approximately $60 \%$ were pronounced dead at the MF while not admitted as an inpatient. The death certificates then record the "place of death" by SIDS as occurring at the MF where the infant is officially pronounced dead, generating the artifact [1]. It is interesting to note that a few SIDS infants are shown to have been declared dead at a hospice facility and nursing homes, which may be where the infant was taken for help.

In summary it is recommended that in cases of SIDS that the death certificate should show, in addition to the location where the death is pronounced, the location where the infant was first found nonresponsive if these locations differ.

\section{References}

1. U.S. Centers for Disease Control and Prevention. http://www.cdc. gov/nchs/data/misc/hb_cod.pdf (2003). Accessed 22 June 2012.

David T. Mage: Retired.

D. T. Mage $(\bowtie)$

World Health Organization, 18 W. Periwinkle Lane, Newark,

DE 19711-6212, USA

e-mail: magedonner@aol.com 